Res Mobilis Revista internacional de investigación en mobiliario

\title{
ARTES DECORATIVAS PARA TIEMPOS MODERNOS (1918-1936). JUAN JOSÉ Y EL CUBRERRADIADOR \\ DECORATIVE ARTS FOR MODERN TIMES (1918-1936). JUAN JOSÉ AND THE RADIATOR COVER
}

$\mathrm{M}^{\mathrm{a}}$ Antonia Herradón Figueroa* Museo del Traje Centro de Investigación del Patrimonio Etnológico

\section{Resumen}

Juan José García (Madrid, 1894-1962), uno de los grandes desconocidos del panorama artístico español, desarrolló la primera parte de su carrera entre 1918 y 1936. A lo largo de esas décadas, decisivas para la renovación de las artes decorativas españolas, Juan José creó a partir del hierro y otros metales un sugestivo muestrario de muebles destinados a cubrir y ornamentar el radiador. El estudio analiza el alcance de esta producción, gracias a la cual también en España el cubrerradiador fue soporte plástico de la modernidad y ejemplo perfecto del estilo art decó.

Palabras clave: Metalistería artística española, cubrerradiadores, art decó, Juan José.

\section{Abstract}

Juan José García (Madrid, 1894-1962), one of the least known artists in Spain, developed the first part of his career between 1918 and 1936. Over these decades, critical to solve the renovation process of Spanish Fine Arts, Juan José created by iron and other metals an engaging ensemble of furniture in order to cover and garnish the radiator. The essay analyses the scope of this production, which turned the radiator cover, also in Spain, into an art support of modernity and into a fine example of style Art Deco.

Keywords: Spanish Ironwork, Radiator Covers, Art Deco, Juan José.

\footnotetext{
*E-mail: mantonia.herradon@mecd.es
} 


\section{Introducción}

A pesar del desconocimiento que sigue persistiendo tanto en relación a su figura como en lo que respecta a su campo de trabajo, Juan José es, sin lugar a dudas, uno de los nombres más interesantes del panorama artístico español de la primera mitad de la pasada centuria. Consumado dibujante, poseedor de una extraordinaria técnica, estaba especializado en el trabajo de los metales en general y del hierro en particular. Su medio siglo de actividad ininterrumpida se materializó en una extensa nómina de objetos que incluye desde anuncios publicitarios hasta postales de guerra, pasando por joyas, orfebrería religiosa, lámparas, relieves, rejería, mobiliario o medallas, y que en su conjunto constituyen un valioso testimonio de las artes decorativas españolas contemporáneas. La primera parte de su carrera transcurrió entre 1918 y 1936, un período tan decisivo para su trayectoria profesional, como para la transformación de las artes aplicadas españolas, oscilantes entre la influencia historicista dominante, que buscaba definir y utilizar un estilo pretendidamente nacional, español o castizo, y la necesidad de plasmar sobre todos los objetos que participaban de la vida cotidiana un estilo moderno, según lo venían haciendo los países europeos de nuestro entorno casi desde comienzos del siglo. No hay que olvidar, además, que, en 1925, ecuador de tan sugestivo período, tuvo lugar en París la Exposititon International des Arts Décoratifs et Industriels Modernes, quintaesencia y cumbre del denominado estilo art decó, que no es sin embargo tanto un estilo artístico al uso como un espíritu modernizador que se desplegó en todos los aspectos de la vida cotidiana del momento.

En ese tiempo Juan José fue testigo privilegiado y actor protagonista, manteniendo pese a las aparentes contradicciones un verdadero idilio con nuestras artes industriales o, como se decía entonces, con los bellos oficios. El objeto de este estudio, su trabajo en torno al cubrerradiador en cuanto soporte plástico, es ciertamente una pequeña parte de su producción, pero también es un ejemplo notable de la intensidad de ese romance, así como de la elevada categoría artística y la modernidad que las artes aplicadas llegaron a alcanzar en España durante los años previos a la Guerra Civil.

\section{El cubrerradiador, entre la tradición y la modernidad}

Desde los mismos inicios del siglo XX el hierro estaba viviendo en toda Europa una auténtica edad de oro, gracias a la cual se convirtió en materia prima indispensable para las artes decorativas, en especial para todas aquellas relacionadas con la arquitectura y la ornamentación de interiores. Y Juan José, artista cincelador por excelencia, situado en la estela de los grandes rejeros renacentistas españoles, supo vincular ese metal tanto con el ámbito más antiguo o clásico de la rejería, transformando y actualizando su lenguaje, como con los nuevos y variados contextos directamente ligados a la vida moderna, caso de la iluminación y de la calefacción. El mobiliario relacionado con la calefacción 
incluye, por un lado, campanas, placas, pantallas, morillos, braseros y defensas, todos los cuales giran en torno a la chimenea, considerada desde tiempos remotos el foco emisor de calor por antonomasia. Por otro se encuentra el cubrerradiador, un mueble concebido en los albores del siglo XX para ocultar y decorar un aparato emisor de calor formado por un número variable de tubos. Pero si bien la producción del madrileño fue notable en relación a los primeros, los datos que se conocen indican que, entre 1918 y 1936, tuvo bastantes más oportunidades de aplicarse sobre el segundo. Era en cierto modo un signo de los tiempos, porque en los espacios interiores en general y en los hogares en particular la chimenea fue perdiendo protagonismo precisamente a partir de la presentación, en la Exposición Universal de París de 1900, del sistema de calefacción central formado por una caldera, tuberías y radiadores de fundición. La progresiva implantación en España de esta novedosa técnica tuvo lugar a partir de 1910 y llevó aparejada, al igual que en Francia, la posibilidad de cubrir con celosías ornamentales unos aparatos de fabricación industrial, ideados por los ingenieros y, en consecuencia, desprovistos por lo general de decoración ${ }^{1}$. Esta solución de carácter estético, que tuvo la virtud de poner en contacto por primera vez esos dos ámbitos en apariencia irreconciliables, no estuvo sin embargo exenta de polémica $\mathrm{y}$, de hecho, nunca llegó a resolverse a gusto de todos ${ }^{2}$.

Desde un punto de vista funcional y conceptual, el cubrerradiador presenta muchas coincidencias con la reja ya que, al igual que ésta, su papel principal es aislar y comunicar al mismo tiempo. También con el lienzo, ya que es un plano que recibe una esmerada decoración dibujada, recortada e incluso coloreada gracias al uso de metales de tonalidades distintas o a la aplicación de pátinas. Del mismo modo se aproxima a la escultura, en cuanto se presenta como un relieve repujado y cincelado. Como se verá, entre las fechas acotadas Juan José desarrolló sobre su superficie, de acuerdo con el eclecticismo de los tiempos, un repertorio decorativo heterogéneo, determinado por las diversas corrientes estéticas vigentes en la España de la época, e inspirado en todo tipo de asuntos figurativos y geométricos. El artista puso así de manifiesto su devoción hacia los aspectos decorativos y narrativos del arte, plasmando sobre el hierro hasta los más pequeños detalles de las formas y asuntos que le inspiraban.

Para este entorno tan específico el madrileño concibió a partir del hierro, en combinación con otros metales como el bronce, piezas únicas, adaptadas a espacios y exigencias concretos, en cuyo aspecto definitivo se dan cita, por un lado, su talante estético personal y su extraordinario virtuosismo técnico, y por otro, el gusto artístico y el interés particular de cada cliente. Al margen de diseños en apariencia no ejecutados, el madrileño firmó unos cuarenta cubrerradiadores, unas obras que informan de distintas sensibilidades estéticas, de manera que no es posible agruparlas bajo el clásico concepto de estilo, en cuanto sinónimo de uniformidad, tan ligado a la historiografía del arte más academicista. Pero si precisamente esta falta de estilo unitario es la característica que las convierte en piezas decididamente contemporáneas, reflejo de los tiempos, la técnica utilizada por el artista para su ejecución, basada salvo raras excepciones en el trabajo manual de cincelado, repujado y recortado, las pone en conexión con la tradición histórica española del trabajo artesanal del 
hierro. Fue esta una elección personal y muy meditada de Juan José, precisamente cuando en toda Europa, pero sobre todo en Francia, estaba más candente que nunca el debate sobre la conveniencia, o no, del uso de métodos puramente industriales, tales como la estampación, la cizalla mecánica, el taladro eléctrico o la soldadura autógena, en el contexto de la creación artística ${ }^{3}$. Así pues, del mismo modo que en la obra de otros artistas coetáneos y que en otras facetas de la producción de Juan José, también en este mueble cobertor se dan la mano la tradición, merced a la artesanía derivada de las técnicas manuales utilizadas, y la modernidad, focalizada tanto en el propio soporte como en su decoración, plasmada mediante un lenguaje artístico contemporáneo.

El análisis y estudio de estas piezas plantea, no obstante, ciertas dificultades derivadas en primer lugar de su relativamente corta vigencia temporal como soporte plástico, un período que, en líneas generales, se extiende en Europa desde la segunda década del siglo XX hasta el estallido de la Segunda Guerra Mundial, pero que en el caso de España llegaría a su término en 1936. A ello hay que añadir la radical transformación sufrida por los interiores de la época, de manera que, al igual que otros elementos del mobiliario contemporáneo, el cubrerradiador ha sido víctima de destrucciones fortuitas, consecuencia por ejemplo de nuestro conflicto civil, o intencionadas, resultado de la constante renovación arquitectónica y decorativa experimentada en espacios públicos y domésticos a lo largo de la segunda mitad de la pasada centuria. Por ello son muy pocos los muebles de esta naturaleza que se han conservado en España y menos aún, por no decir ninguno, los que se han mantenido en su ubicación primigenia ${ }^{4}$. De ahí el extraordinario interés que revisten para la investigación los diferentes diseños presentados por Juan José a los clientes; también sus dibujos de taller a tamaño natural del modelo elegido, destinados a trasladar al metal el motivo a cincelar; y, desde luego, las fotografías de las piezas una vez terminadas ${ }^{5}$.

\section{El cubrerradiador en la década de $\mathbf{1 9 2 0}$}

Aunque algunas informaciones apuntan a que el primer trabajo de esta naturaleza realizado por Juan José podría datar de 1918: se trata de uno o varios cobertores encargados por Nicolás María Urgoiti Achúcarro para su domicilio de la madrileña calle Jorge Juan ${ }^{6}$, unas piezas decoradas al parecer con motivos vegetales que todavía se conservan, aunque fuera de su contexto original, de las que poco más se sabe por el momento. De ahí que el ejemplo más antiguo identificado con seguridad sea un diseño ${ }^{7}$ de estética historicista, cuyo plano frontal, enmarcado por varillas retorcidas y apoyado en patas sencillas, presenta una decoración calada de inspiración neorrenacentista a base de grutescos, organizados en torno al busto de un guerrero en tondo, que juegan con la simetría, el movimiento y la monstruosidad (Fig. 1). No hay datos que indiquen que la propuesta se materializara finalmente, aunque es posible que fuera concebida, al menos en teoría, haciendo juego con una pantalla de chimenea ornamentada de forma similar ${ }^{8}$ y que sí fue ejecutada, aunque su comitente y su paradero actual son desconocidos ${ }^{9}$. La estética de estos dos muebles era 
absolutamente acorde con los estilos ornamentales dominantes en la España del momento, por lo demás promocionados convenientemente en los tratados arquitectónicos y en los repertorios decorativos al uso, de manera que durante bastante tiempo fueron considerados perfectamente adecuados para ser instalados en hogares aristocráticos y burgueses, incluso en una fecha tan avanzada como la tercera década del siglo ${ }^{10}$.

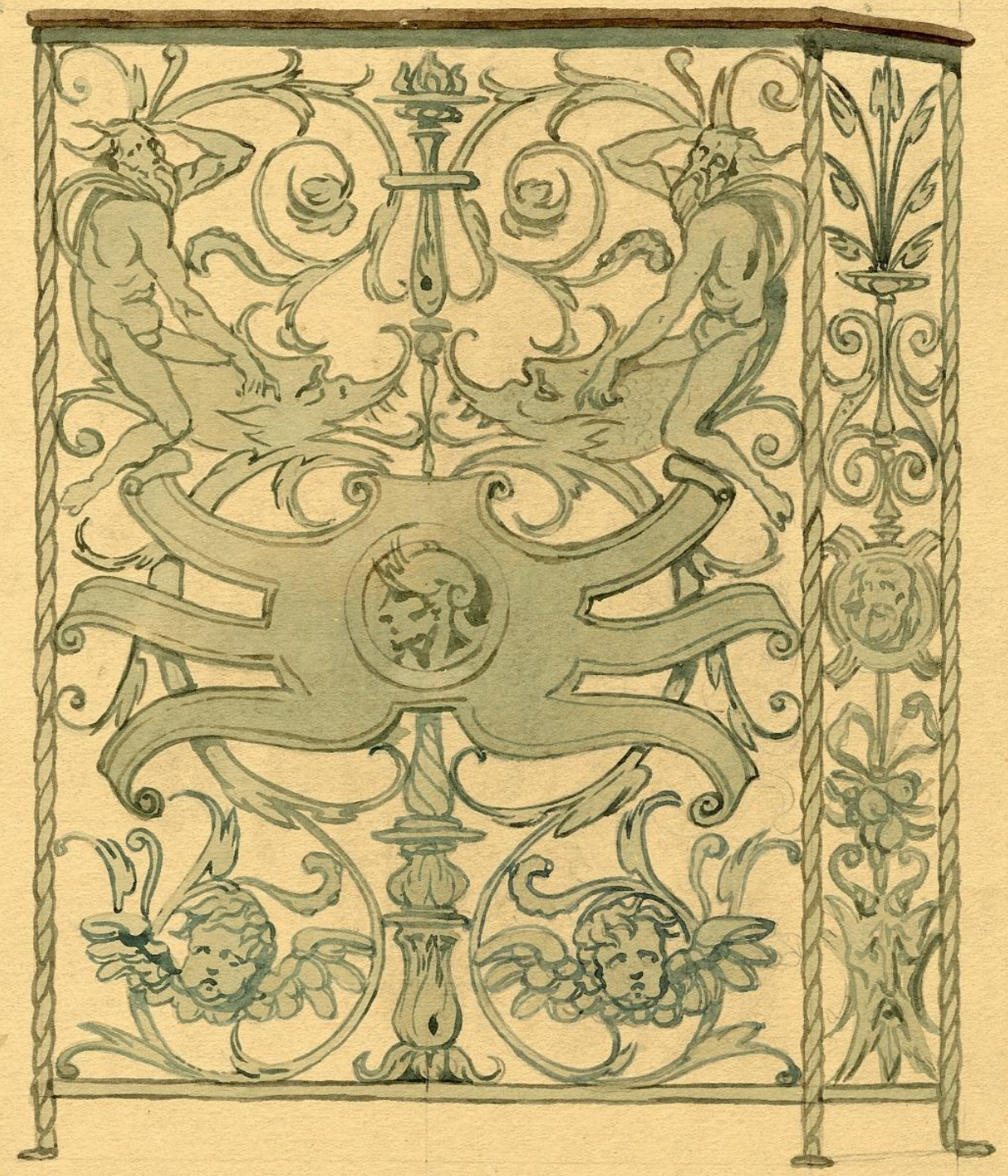

Fig. 1. Diseño de cubrerradiador de estilo neorrenacentista, 1920-1923. Tinta y acuarela. (C) Museo del Traje, CIPE (Madrid). 
Sin embargo, parece que en manos del madrileño este modelo de inspiración historicista dejó paso, pronto y sin solución de continuidad, a otros de estética bien diferente, imbricados ya en la contemporaneidad. Es plausible que la oportunidad se presentara con motivo de la construcción de su vivienda y taller en 1923. Guarneció entonces al menos dos de los radiadores de la casa -muy probablemente los ubicados en la sala donde recibía a los clientes- con estos muebles cobertores, optando por una decoración sencilla y depurada, basada en motivos no estrictamente novedosos que, sin embargo, supo refinar y organizar a modo de frisos continuos calados que dan sensación de orden, ligereza y modernidad, situándose por tanto a mucha distancia estética de las piezas historicistas comentadas. Ambos muebles se han conservado, lo que permite conocer las técnicas utilizadas por el artista tanto para conformarlos como para decorarlos. Su estructura está compuesta por cintas de hierro lisas o rizadas, cinceladas, que arman una especie de marco, prolongado hasta formar unas pequeñas patas en forma de voluta, sobre el que se sujetan mediante clavos los planos decorados; la tapa es de mármol. Uno de ellos desarrolla en su cara principal un diseño a base de volutas enfrentadas, recortadas y cinceladas individualmente y luego soldadas ${ }^{11}$ entre sí, provistas de volumen mediante el cincelado de líneas paralelas a modo de gallones (Fig. 2), mientras que en la lateral muestra grandes hojas estilizadas de formas geométricas y bordes en zigzag; un eclecticismo iconográfico y estilístico que incidiría el posible carácter de muestrario que pudo tener la pieza. El segundo utiliza un motivo vegetal simplificado, enfatizado mediante líneas cinceladas, recortado y trabajado por el contrario en una única plancha de metal ${ }^{12}$. Por su parte, una tercera propuesta coetánea para el mismo entorno se basa en una serie de cruces de brazos curvos enmarcadas en cuadrados ${ }^{13}$. En todos los casos Juan José juega con ornamentaciones estilizadas o geometrizadas, un estilo decorativo que asimismo aplicaría sobre otro cubrerradiador fechado también en 1923, cuyo comitente y paradero se desconocen ${ }^{14}$. 


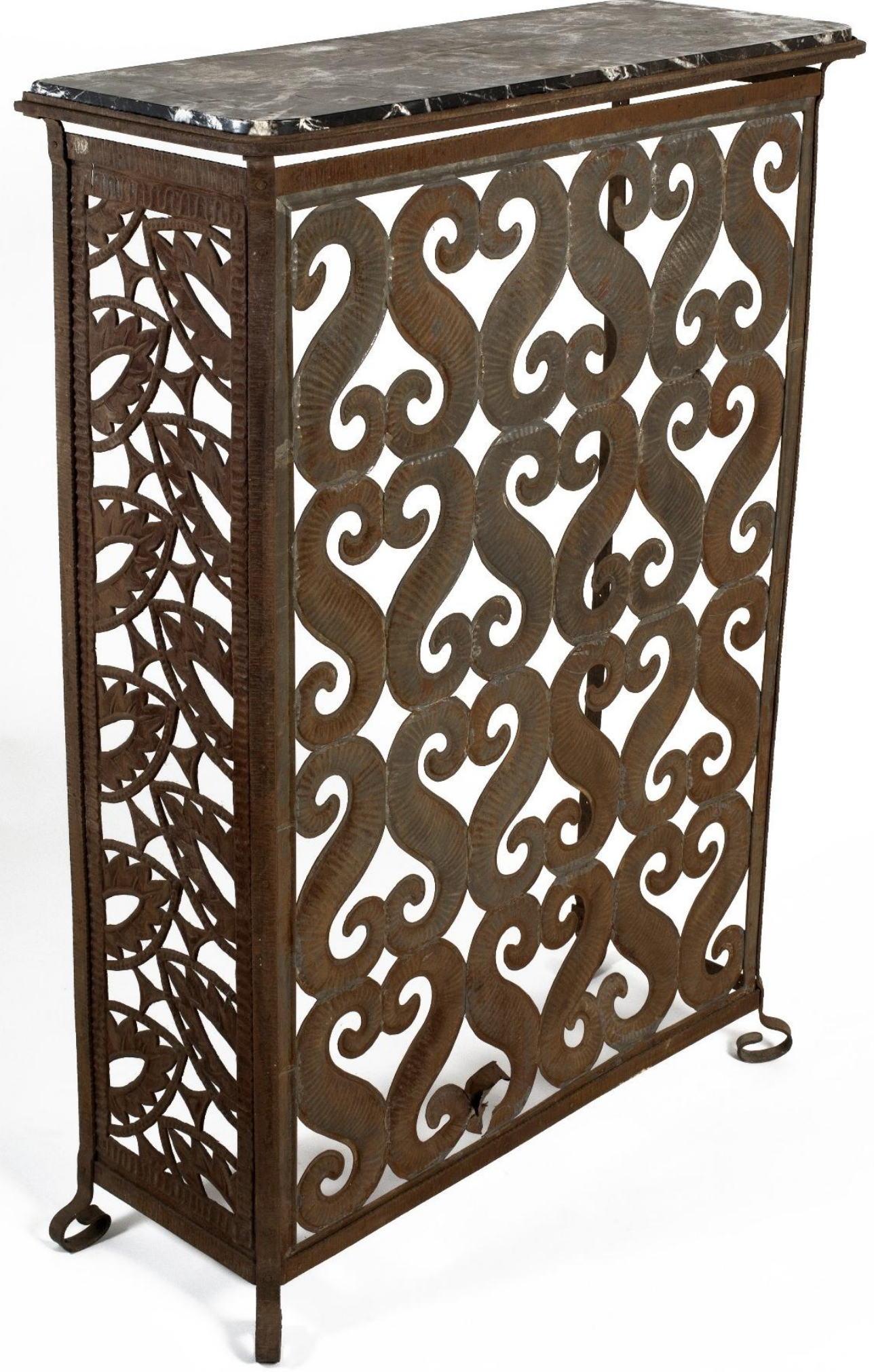

Fig. 2. Cubrerradiador, 1923-1924. 105 x 74 x $29 \mathrm{~cm}$. @ Museo del Traje, CIPE (Madrid). Javier Rodríguez Barrera. 
En esta ocasión la renovada concepción estética se pone de manifiesto en varios aspectos que se complementan entre sí. Por un lado, en la propia disposición de la decoración, ya que el plano frontal está dividido mediante cintas rizadas en compartimentos pentagonales y rectangulares organizados en torno a un octógono central. Por otro, en su iconografía, ya que desarrolla un repertorio de animales (grulla, loro, espátula y tucán en las esquinas; canguro en el centro) propios de ámbitos geográficos muy alejados del occidente europeo, rodeados de una vegetación asimismo exótica. Finalmente, también es moderno el tratamiento de la decoración: en el caso de los animales, de contenido clasicismo, destaca el gran nivel de detalle con el que están resueltos, solución que ofrece un sugestivo contraste tanto con los vanos de cada escena como con las sintéticas líneas, casi gráficas, que evocan los respectivos entornos naturales. Y es en estos motivos vegetales donde asimismo se advierten interesantes influencias estéticas no occidentales ni tampoco estrictamente académicas, las cuales van desde la pintura japonesa hasta las estilizaciones florales propias de los bordados populares españoles. Algo similar ocurre en los paños laterales del mueble, para los que Juan José diseñó un motivo de hojas lanceoladas de depurada geometría ${ }^{15}$. El resultado final es un mueble decorado como si se tratase de un lienzo dibujado y recortado, pero también como si fuera un relieve escultórico repujado y cincelado.

Tras su concurrencia a la emblemática Exposición de Artes Industriales y Decorativas, celebrada en París en 1925, en calidad de artista expositor en el pabellón español ${ }^{16}$, su trabajo en relación al cubrerradiador se intensificó de manera considerable. Este incremento debe ponerse en relación, en primer lugar, con el hecho de que en la capital francesa fue testigo directo de las infinitas posibilidades expresivas del hierro, un material omnipresente en todos los pabellones expositivos sin excepción lo que, a todos los efectos, le condujo a erigirse en el verdadero rey del certamen. Además de los que se mencionarán más adelante, algunos ejemplos del indiscutible protagonismo alcanzado por el hierro en la muestra parisina son el Pavillón de la Ville de Paris, el Pavillon de la Cie. Asturienne des Mines, el Pavillon du Collectionneur o el Pavillon de l'Elégance, a los que hay que añadir la aportación, a menor escala, pero no por ello menos significativa, de las boutiques de Paul Dumas, Mme. Pangon, Alexandre, Siegel o Têtard. Es de suponer, además, que en este contexto tan estimulante examinara los singulares ejemplos de muebles cobertores para el radiador exhibidos en varios de los pabellones del recinto. Hay que recordar que este soporte plástico, en paralelo a la propia expansión del hierro y otros metales, estaba viviendo en Francia una época gloriosa gracias al creativo empuje de un extraordinario elenco de ferronniers d'art, en el que destacaban nombres como Paul Zsabo, Paul Kiss, Charles Piguet, Edouard Schenk, Richard Georges Desvallières, los hermanos Majorelle, la Société des Hauts Fourneaux et Fonderies de Brousseval, los Établissements Schwartz-Hautmont y, sobre todo, Raymond Subes y Edgar Brandt. Así, por ejemplo, Subes firmaba el ubicado en el comedor principal del pabellón denominado Une ambassade française, una fantasía de cintas forjadas con texturas diferentes, entre las que se distribuían 
simétricamente agrupaciones florales, que además formaba conjunto con un aplique de luz. Por otra parte, Kiss presentó en una de las tiendas erigidas en el puente Alejandro III el cobertor Le faisan, en donde el ave mostraba su plumaje y su larga cola rodeado de flores y frutos. Y en el pabellón Région de Nancy et de l'Est se exhibió un cubrerradiador de Majorelle, en el que se combinaban cintas, dientes de sierra y perlas de hierro forjado con un soberbio zócalo de ónice rojo. No hay que olvidar, además los expuestos al margen de la arquitectura propiamente dicha, es decir, en el área dedicada a los trabajos de metal, caso de una pieza de Schenk de hierro y cobre forjados. Así pues, en París las fuentes de inspiración fueron ilimitadas, y a partir de ellas Juan José dio rienda suelta a su creatividad desde parámetros cada vez más modernos, desarrollando un estilo que, además, y esto es lo más interesante, supo seducir a sus clientes madrileños.

De este fructífero contacto da fe el nutrido grupo de cubrerradiadores que firmó en segunda mitad de los años veinte. De algunos de ellos no hay información más allá de la que se desprende de los cuadernos donde el artista anotaba el nombre de los comitentes y las características generales del encargo, tales como sus dimensiones o su ubicación en el inmueble. Gracias a esas notas sabemos que, por ejemplo, en 1926 diseñó cobertores para los radiadores del salón de actos del recién fundado Lyceum Club Femenino17, así como para los domicilios particulares de Joaquín Martínez Friera, Guillermo Ullmann y Ezequiel de Selgas, todos ellos ubicados en la ciudad de Madrid.

Por el contrario, en el caso de otras piezas fechadas entre 1926 y 1928, sí se conoce su apariencia aunque nada se sepa del comitente. Nuevamente son los diseños, los dibujos de taller y las fotografías las que informan sobre ellos, porque en general son piezas cuyo paradero, salvo algún caso aislado, es desconocido. Una de estas excepciones es el mueble decorado con una escena de la vida de Genoveva de Brabante, cuyo panel frontal es actualmente propiedad del Museo del Hierro de Oropesa del Mar ${ }^{18}$. La heroína medieval, hija del duque de Brabante y esposa de Sigfrido, conde palatino de Tréveris, fue acusada de adulterio y condenada a muerte; logró escapar y se refugió en el bosque con su hija, que fue amamantada por una cierva. El artista la representa de pie, trazando una leve contraposición, dotándola de una silueta estilizada, y simplificando y geometrizando su rostro, su cuerpo semidesnudo y, sobre todo, los paños que la cubren; tras ella asoma la coprotagonista de la escena, una elegante gacela $^{19}$. La composición, situada en un bosque evocado mediante árboles y plantas esquematizados, se completa con una leyenda identificativa (fig. 3). 

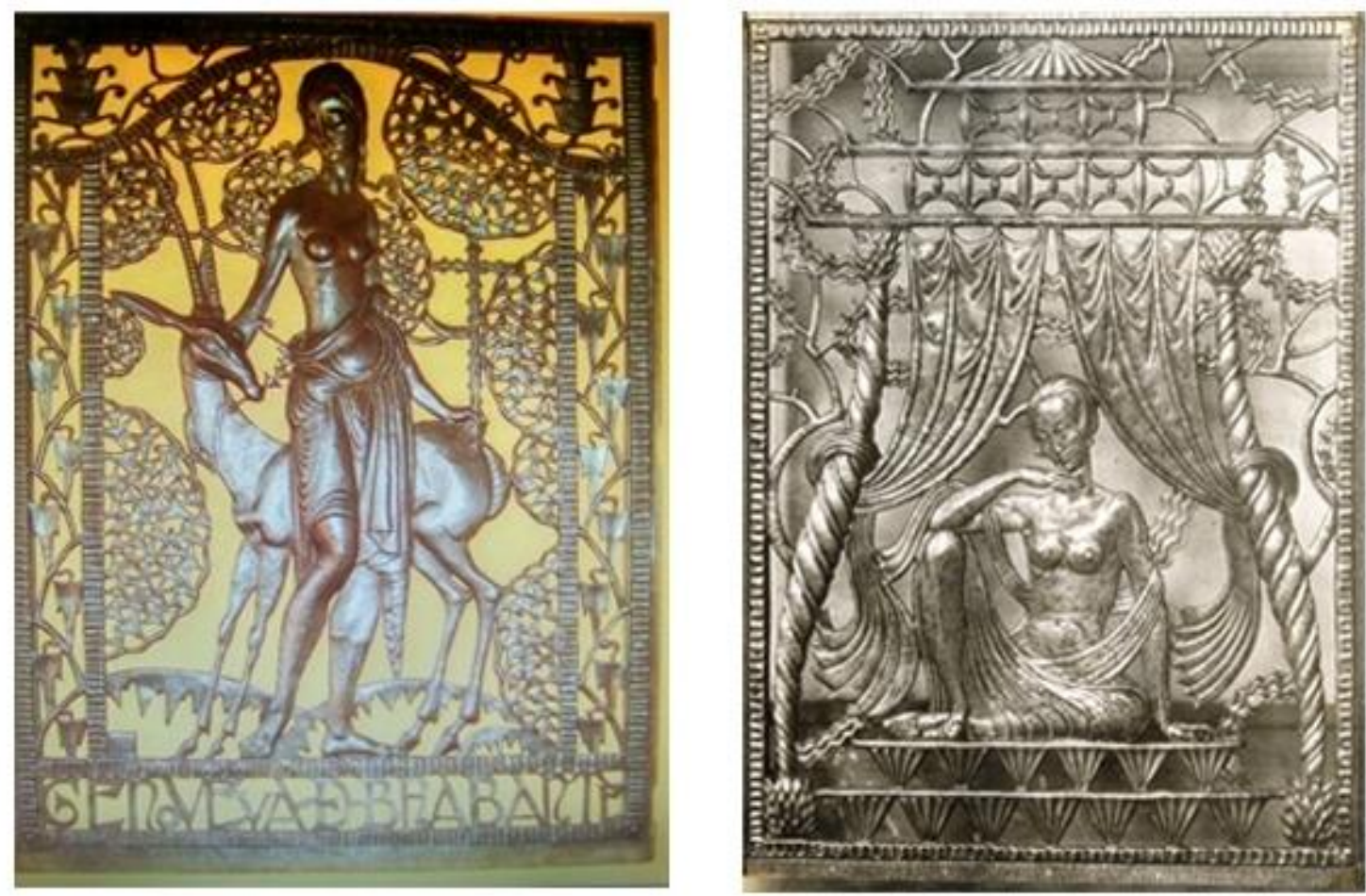

Fig. 3. Genoveva, 1926. (C) Museo del Hierro de Oropesa del Mar. Kiosko, 1926. Fotografía. (C) Museo del Traje, CIPE (Madrid).

En sus notas el artista registra esta obra como Radiador [sic] moderno Genoveva, una manera inequívoca de identificarla y de singularizarla y, en el fondo, de equipararla mediante un nombre propio a la pintura y a la escultura. Se trata de un guiño en el que, quizás, también quepa atisbar la influencia de los ferronniers franceses en general y de Brandt en particular, cuyos cubrerradiadores ostentaban ya por entonces títulos tan evocadores como Les pins, Les fruits, Les Marguerites, Les fleurs, Les bouquets o La biche dans la forêt. Puesto que era relativamente habitual en la época que los cubrerradiadores se diseñaran en parejas, esta pieza pudo formar conjunto con la titulada por el artista Radiador [sic] moderno Kiosco. Su frontal presenta una muchacha de elegante anatomía, torso desnudo, falda de pliegues clásicos y peinado a lo garçon, sentada bajo un kiosco de estética oriental adornado con cortinas de profundos pliegues y rodeado de estilizada vegetación en la que destacan los perfiles zigzagueantes de los árboles ${ }^{20}$.

Los que con total seguridad sí conformaron una unidad son los decorados, respectivamente, con una ménade tocando los crótalos, y un sátiro tañendo los címbalos, ambos bailando, resueltos con planos más geométricos que en las piezas precedentes, los cuales marcan de forma notable rasgos faciales, anatomía y vestiduras. En ambos casos destaca el acierto de la composición a base de una diagonal sinuosa que, unida a los estilizados roleos que pueblan el fondo de la composición, dota al conjunto de un profundo sentido del ritmo. Como viene siendo habitual, las cintas de metal martilleadas que rodean a cada personaje funcionan del mismo modo que lo haría un marco convencional en una pintura: 
acotan y enmarcan un trabajo que, fuera del contexto apuntado, podría interpretarse sin problemas como un relieve escultórico. Su paradero actual se desconoce $^{21}$. También forman pareja otros dos cobertores que, por otra parte, en la trayectoria del artista suponen un paso más allá a la hora de desarrollar las posibilidades expresivas del metal aplicadas a la decoración doméstica. En ellos se combinan, al más puro estilo Brandt, dos materiales: el hierro y el bronce, un recurso técnico y formal que, no obstante, Juan José ya venía explotando desde al menos un lustro antes en diversas obras de pequeño formato. Utilizó el primero para forjar los marcos, así como para cincelar y repujar la gacela en actitud de salto y la grulla en pleno vuelo. Los animales destacan por presentar equilibradas dosis de realismo y dinamismo, mientras que la tierra y el mar representados se han reducido a sus líneas esenciales. Y para forjar el sol, el verdadero protagonista de unas escenas narrativas que, una vez más, aúnan valores escultóricos y pictóricos, el artista aprovechó las cualidades cromáticas del bronce y su brillo 22 (Fig. 4).
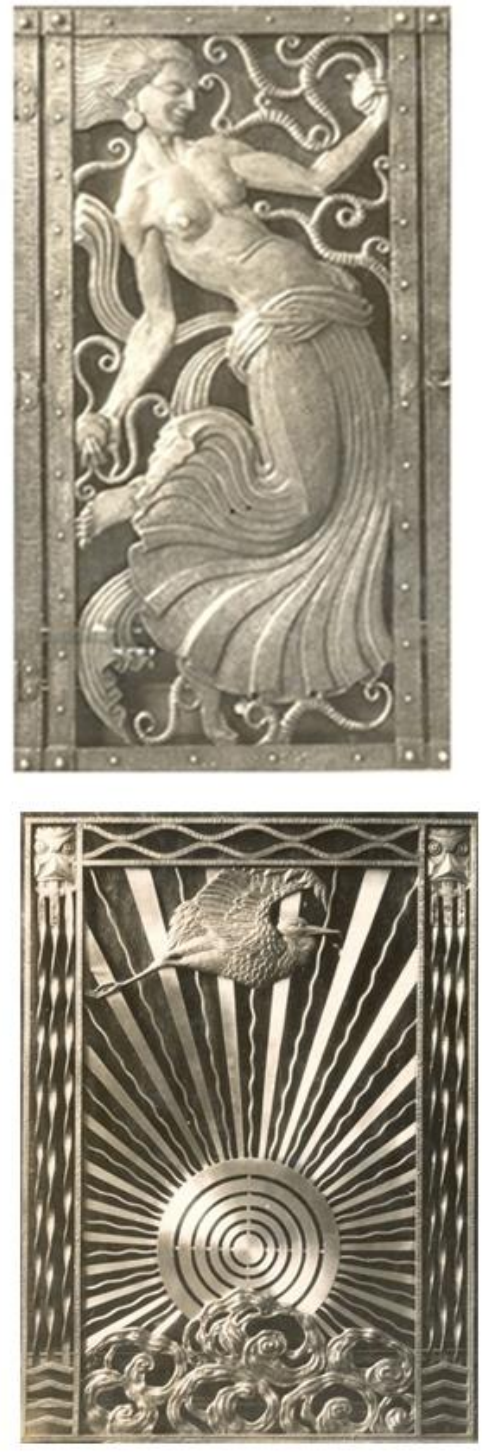
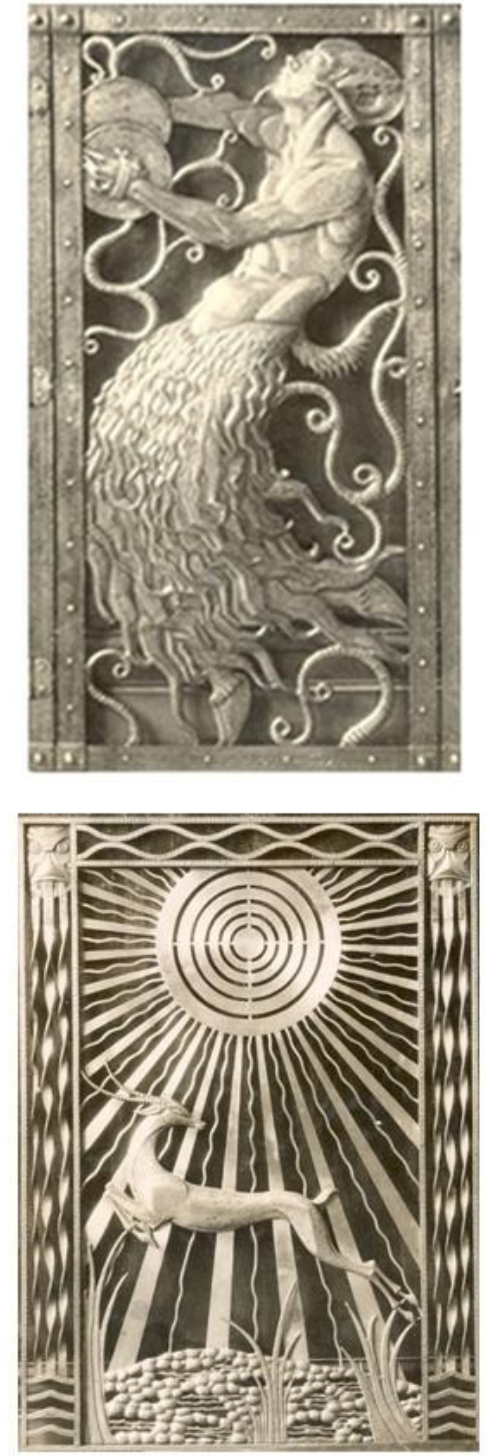

Fig. 4. Ménade y Sátiro, 1926. Ocaso y Cénit, 1928. Fotografías. (c) Museo del Traje, CIPE (Madrid). 
Tres piezas cierran el repertorio de cobertores realizado por Juan José en la década de 1920. La primera de ellas estuvo instalada en su casa, siendo por tanto uno de los pocos que se han conservado ${ }^{23}$. Presenta una decoración basada en el conocido poema de Baudelaire L'inspiration du voyage, cuyos primeros versos "Mon enfant, ma soeur songe à la douceur d'aller là-bas vivre ensemble" figuran en una filacteria. Está protagonizada por una pareja ataviada a la moda de mediados del siglo XIX, aunque de líneas muy estilizadas, en absoluta consonancia con ciertos dibujos que los ilustradores contemporáneos publicaban en la prensa del momento y con los figurines que mostraban la moda coetánea de más rabiosa actualidad. Similar estilización -que adquiere tintes geométricos en las hojas- se advierte en el tratamiento de las plantas, palmeras y nubes que dan forma al paisaje de la escena (Fig. 5). Destaca especialmente en este trabajo la evocación que el artista propone de las texturas de las diferentes materias, realizada mediante un variado repertorio de toques de cincel, una técnica que dota al relieve de un carácter singularmente pictórico. La pieza está firmada, como el resto de muebles de este tipo y, en general, como todos los trabajos del artista anteriores a la Guerra Civil, en el ángulo inferior izquierdo del panel frontal.

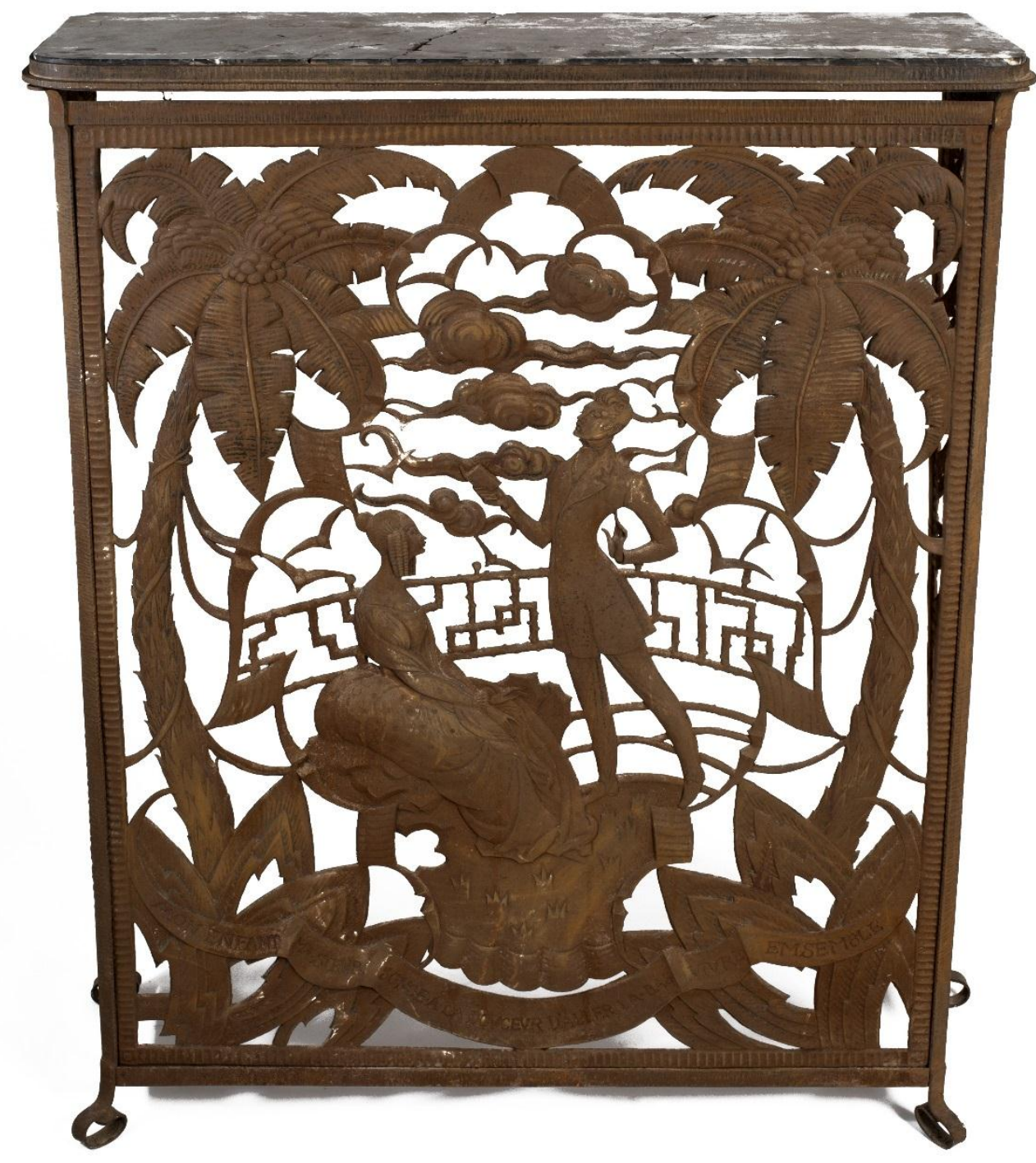

Fig. 5. Invitación al viaje. 1927. 105 x 85 × $29 \mathrm{~cm}$. (C) Museo del Traje, CIPE (Madrid). Javier Rodríguez Barrera. 
La segunda rindió tributo en 1928 a la mascota del comitente, el arquitecto Amós Salvador Carreras ${ }^{24}$. En el centro de la composición, organizada -como si de un retablo se tratase- en tres registros verticales subdivididos a su vez en cuadrados, figura un perro identificado con la leyenda Micki. Se trata de otro relieve, en el que predominan los asuntos florales como lotos y campanillas, vegetales y animales, geometrizados y dispuestos simétricamente en torno al homenajeado, tratado con mayor realismo que aquéllos ${ }^{25}$. Por último, hay que mencionar las encargadas en 1929 para diversas estancias de la Estación del Norte de Madrid, todas ellas actualmente en paradero desconocido ${ }^{26}$. La destinada al despacho del director presenta una serie de rectángulos secantes con cuadrados macizos en sus vértices que, a modo de las muñecas rusas, acaban abrazando a un octógono central en el que figuran dos pájaros. Es un diseño caracterizado formalmente por su sobriedad geométrica y, desde un punto de vista decorativo, por la textura casi textil que el cincelado imprime a toda la superficie del metal.

\section{El cubrerradiador en la década de $\mathbf{1 9 3 0}$}

Según atestiguan los modelos presentados no hay dos cubrerradiadores iguales, ni siquiera parecidos salvo, claro está, cuando fueron concebidos como una unidad. Se trata, pues, de piezas únicas, trazadas de acuerdo con las preferencias iconográficas y los gustos estéticos del cliente. Esta característica se mantuvo durante la década siguiente, cuando este soporte conoció en manos de Juan José su tiempo de máximo esplendor. Sobre él desplegó todos los asuntos favoritos del momento, caso por ejemplo de los cuernos de la abundancia ${ }^{27}$, que el artista venía plasmando desde hacía tiempo en dibujos publicitarios, lámparas, bandejas, etc. Otra de esas imágenes se articula en torno a las flores, bien sueltas, bien dispuestas en cestos, formando ramos o colocadas en jarrones. En ocasiones son composiciones evocadoras de formas barrocas, mientras que en otros casos fueron depuradas por el artista hasta alcanzar una gran contención formal y un indiscutible carácter decorativo moderno. Dos ejemplos ilustran bien las posibilidades de esta iconografía. El primero desarrolla una composición a base de margaritas sobredimensionadas y grandes hojas perfiladas en zigzag, un modelo del que el artista realizaría dos variantes, incorporando en una de ellas una gran tela de araña ${ }^{28}$. El segundo decora un frontal conservado en el Museo del Hierro de Oropesa del Mar, y muestra una gran cesta con asa ${ }^{29}$, rodeada de cintas y enmarcada por dos golondrinas, que contiene ramas a modo de roleos salpicadas con menudas campanillas. Se trata, en definitiva, de uno de los temas barrocos por excelencia cuyo diseño el artista ha reinterpretado, sintetizado y estilizado, acercándolo a su tiempo, en línea con numerosos artistas contemporáneos (Fig. 6). 

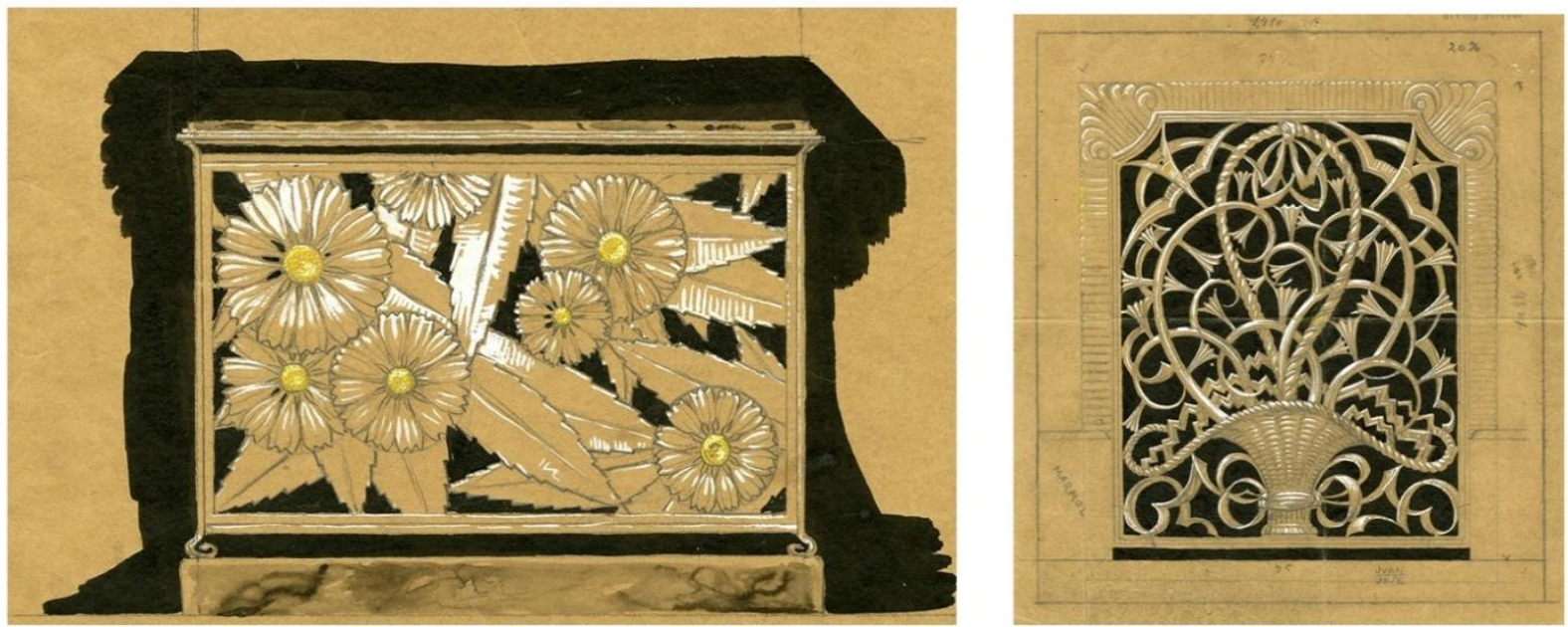

Fig. 6. Margaritas y Cesta, 1930-1936. Lápiz y tinta. (C) Museo del Traje, CIPE (Madrid).

Los animales constituyen el tercer gran grupo iconográfico que figura en los muebles para el radiador fechados en los años previos a 1936. El madrileño los representa formalmente estilizados mediante líneas fluidas y en actitudes muy dinámicas. Y los sitúa en su entorno natural, bien sintetizado, bien reducido a geometrías diversas. Quizás la mejor muestra de esta temática sea la del titulado por el artista Radiador [sic] moderno Cacería, que desarrolla una escena ambientada en la selva, en la que un león se abalanza, trazando una diagonal, sobre la figura masculina de un indígena en actitud de salto. En esta composición resulta muy interesante el tratamiento sintético de los cuerpos de los protagonistas, ambos de músculos muy marcados, que transmiten tensión y movimiento. También es especialmente acertada la evocación de la frondosidad del entorno, conseguida mediante una acumulación de altas palmeras, amplias masas vegetales y grandes hojas, que se conforman con líneas en zigzag y formas apuntadas combinadas con trazos curvos $^{30}$. Idéntico protagonismo de las geometrías se advierte en otra pieza coetánea de temática muy similar, si bien en ella la escena está protagonizada por una pantera que camina sigilosa bajo una composición simétrica de grandes hojas en espiral provistas de bordes dentados ${ }^{31}$ (Fig. 7). La fluidez de las formas del félido dibujado por el artista recuerda sin esfuerzo a la Pantera de Java, la conocida escultura tallada directamente en diorita por Mateo Hernández entre 1922 y 1925, que se expuso delante de la puerta trasera -una monumental pieza de hierro, por cierto, firmada por Juan José $32_{-}$del pabellón español de la citada exposición parisina, y que otros escultores claves del momento como François Pompon y Raymond Delamarre interpretarían posteriormente con estéticas muy parecidas.

En otras ocasiones, sin embargo, aun partiendo de un mismo asunto relacionado con la caza, el artista opta por reducir al máximo las referencias al ambiente el que se desarrolla la escena. Es el caso de una pareja de cubrerradiadores realizados en latón cincelado, que muestran, respectivamente, la figura de un hombre disparando con arco a una leona y una figura femenina perseguida por un león, ambos personajes de rasgos negroides y desnudos (Fig. 
8). Aquí la evocación de la selva ha quedado reducida a una serie de líneas quebradas, salpicadas de pequeños brotes vegetales, que sirven de marco a sendas composiciones diagonales plenas de dinamismo ${ }^{33}$.
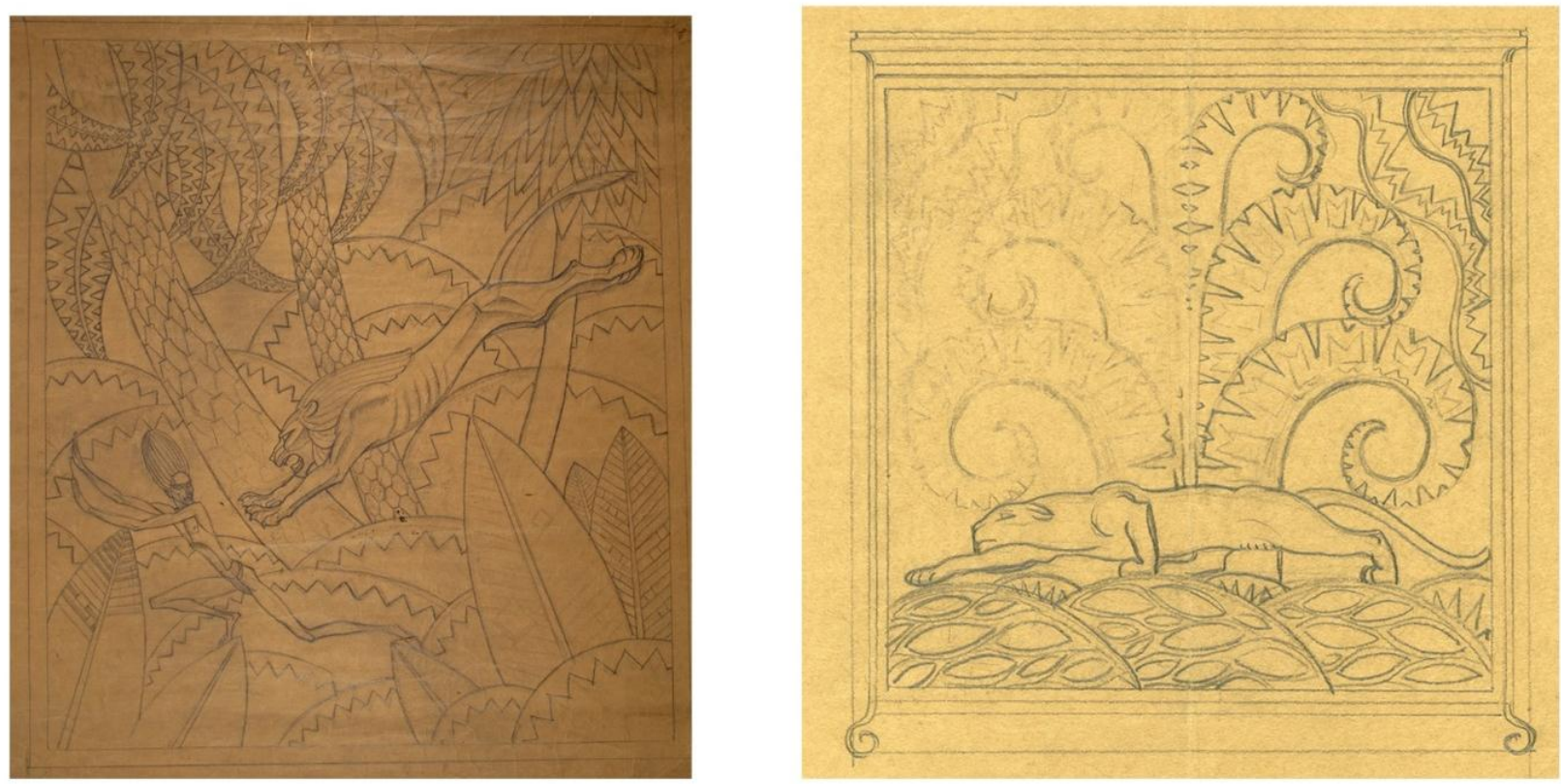

Fig. 7. Dibujos de taller para cubrerradiadores Cacería y Pantera, 1930-1936. Lápiz. @ Museo del Traje, CIPE (Madrid).

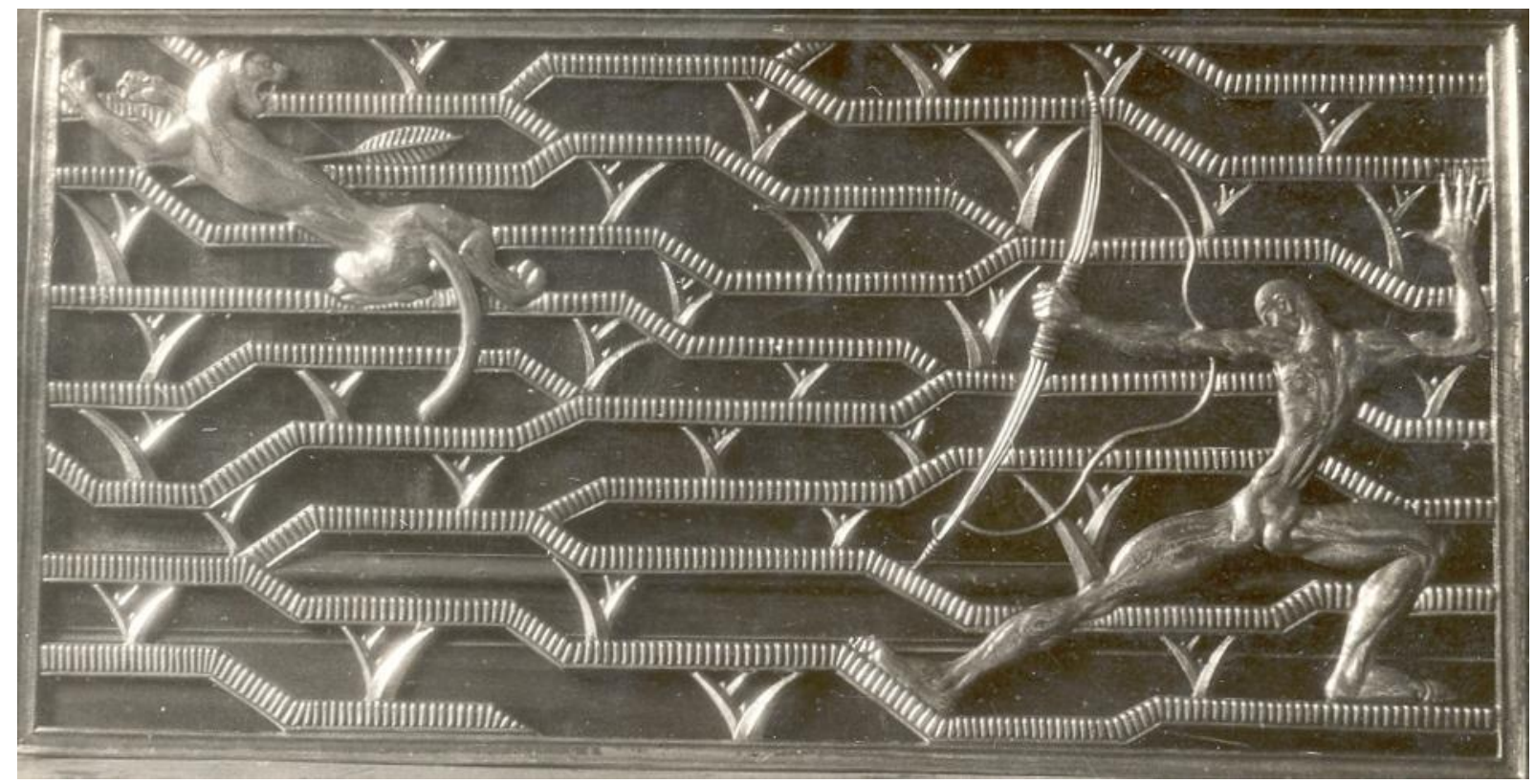

Fig. 8. Cacería (2), 1930-1936. Fotografía. (C) Museo del Traje, CIPE (Madrid). 


\section{El cubrerradiador, soporte plástico para tiempos modernos}

Dejando al margen algún caso aislado ${ }^{34}$, los cubrerradiadores realizados por Juan José se erigen, por el momento, en los únicos representantes españoles de un singular mueble moderno, ideado para cubrir y embellecer el radiador, que en los años previos a la Segunda Guerra Mundial fue muy bien valorado en otros países europeos, especialmente en Francia. A pesar de que todo indica que su implantación en España fue ciertamente limitada, de la mano de Juan José también aquí se erigió en genuino representante de las más novedosas tendencias decorativas del momento. Fue moderno tanto por su concepto como por las fórmulas ornamentales aplicadas sobre él por el artista madrileño. De ahí que, en cuanto signo de los tiempos, constituya un excelente testimonio de la adaptación de la vida cotidiana al arte, un singular ejemplo de lo que el escultor José Clará definió como "el arte viviente de nuestra época para el disfrute de nuestra vida" 35 .

En cuanto soporte plástico su decoración se caracteriza por ser la expresión de la individualidad y sensibilidad personales del artífice, una tendencia característica de esos años que no sólo desarrollaron los ferronniers d'art, sino que también pusieron en práctica todos artistas contemporáneos en general ${ }^{36}$. Así, para conformar su estética personal aplicada al cubrerradiador ${ }^{37}$, un miembro más de la gran familia de las artes decorativas del período de entreguerras, Juan José se inspiró en fórmulas tradicionales, que reinterpretó, depuró, renovó y adaptó a su tiempo. Como resultado de este proceso innovador los cobertores realizados por del madrileño entre 1918 y 1936 muestran prácticamente todo el repertorio iconográfico con el que generalmente se identifica el art decó en buena parte del mundo occidental y, en menor escala, también en ciertos países no occidentales. Pérez Rojas recopiló algunos de esos motivos que identifican el art decó en España, entre los que figuran líneas onduladas, rizos, volutas, círculos, zigzags, triángulos, rayos, volúmenes escalonados, cestas de flores, fruteros, plantas tropicales, así como referencias al arte africano, chino, japonés, griego, popular español y a otras culturas también alejadas en el tiempo y en el espacio ${ }^{38}$. A esta amplísima nómina cabe añadir otros asuntos, quizás más relacionados con el art decó internacional, como los octógonos y los animales, en especial ciervos y gacelas. Todos esos motivos ornamentales que el art decó hizo suyos no eran en realidad nada nuevo, sino que eran elementos procedentes de diversos estilos históricos y de diferentes entornos culturales.

Juan José, como genuino representante del artista de los años de entreguerras, no los rechazó, sino que, por el contrario, los consideró bajo una nueva óptica, recreándolos, modificándolos, aludiendo a ellos con sutileza, con inocencia o con obsesión, rindiéndoles en definitiva un homenaje y situándolos en la modernidad. Así, de la mano del individualismo característico de la sociedad de la época, y con el foco puesto siempre en la búsqueda de la mayor expresividad posible, Juan José, lo mismo que el art decó, acabó encontrando su razón de ser y también su sitio en la delgada línea fronteriza que separa tradición y modernidad. 
Para terminar, señalar que el análisis realizado sobre la producción del artista madrileño en relación a los muebles cobertores para el radiador no puede considerarse finalizado todavía debido a que son muchos y de temática diversa de los que hay noticia, pero que se han desestimado en esta ocasión al carecer de una mínima información contrastada acerca de ellos. Esa circunstancia no debe impedir, sin embargo, que este estudio permita arrojar un poco más de luz sobre una etapa de nuestra historia del arte ignorada sistemáticamente en la bibliografía foránea ${ }^{39}$ y que, por lo demás, todavía no ha sido suficientemente explorada por los investigadores españoles pese a que en los últimos años se han publicado interesantes aportaciones a su conocimiento ${ }^{40}$. Como vienen sosteniendo desde hace décadas entre otros de Diego, Fontbona, Lozano Bartolozzi, Brasas Egido y el citado Pérez Rojas, en el caso de la España de estos momentos también es posible hablar de art decó, es más, se debe hablar de art decó, y además hacerlo en la misma medida que en los países de nuestro entorno. En este sentido no cabe ninguna duda de que, como muestran sus cubrerradiadores, Juan José encaja a la perfección en este movimiento de universalidad deslumbrante: rompió con el concepto clásico de estilo, igual que lo hizo el art decó; modernizó la metalistería artística española; cultivó los estilos históricos con un lenguaje formal moderno que reinterpretaba volúmenes y decoración; y utilizó para ello un lenguaje visual extraordinariamente diverso elaborado a partir de las mismas fuentes que nutrieron las artes decorativas contemporáneas en Europa y América. Por eso de su taller salieron multitud de obras elegantes y sofisticadas, entre ellas unos refinados y modernos cubrerradiadores que deben formar parte del repertorio español y europeo del art decó.

De igual forma que otras muchas piezas que hasta ahora han permanecido ignoradas y que merecen salir a la luz, esta producción artística debería haber aportado su granito de arena a la definitiva integración de España en su época. La meta sin embargo nunca pudo alcanzarse, porque los avances realizados durante la Dictadura Militar y durante la Segunda República no pudieron compensar las décadas de retraso que llevaba el país en este terreno. Tampoco tuvieron la oportunidad de completar su ciclo evolutivo natural debido a la fractura que la vida nacional sufrió a partir de 1936, y que desde luego no invalida los muchos logros alcanzados hasta entonces. Es tiempo, pues, de saldar la deuda que seguimos teniendo con un de los aspectos más desconocidos y olvidados de nuestra historia del arte: las artes decorativas nacidas en y para unos tiempos que fueron decididamente modernos.

\section{NOTAS}

\footnotetext{
${ }^{1}$ En España, los primeros anuncios publicitarios insertados en la prensa ilustrada sobre el método de calefacción central, garantía de confort, economía, higiene, comodidad y limpieza, datan de la segunda década del siglo XX. Están relacionados con la firma francesa Compagnie Nationale del Radiateurs, fabricante del que sería el modelo de radiador más común en toda Europa en la primera mitad de la centuria. En ellos se vincula la calefacción central con la casa unifamiliar, denominada entonces hotel particular, en la época el modelo de vivienda burguesa por excelencia. No obstante, la sustitución del hogar como foco emisor del calor por un sistema de calefacción central fue progresiva. En cuanto elemento históricamente prestigioso, en las estancias
} 
más representativas la chimenea todavía mantuvo protagonismo y función un tiempo, incluso cuando el radiador estaba presente en otras habitaciones. Por tanto, entre 1918 y 1936 en España convivieron ambos sistemas.

${ }^{2}$ Algunos especialistas consideraban que el radiador era, por encima de todo, un perfecto ejemplo de objeto feo. En esta línea CLOUZOT, Henri, Le travail du métal, París, F. Rieder et Cie, Éditeurs, 1921, p. 38-39, opinaba que los cobertores paliaban, pero en ningún caso solucionaban, el problema de tan desafortunada estética, además de suponer un inconveniente para la difusión del calor. Por su parte, VERNE, Henri y CHAVANCE, René, Pour comprendre l'art décoratif modern en France, Paris, Hachette, 1925, pp.111-112, insisten en lo mismo, ya que siguen considerando el cubrerradiador un mero recurso, nunca una solución. De ahí que, en un intento de marcar el camino a seguir, se hagan eco del que consideran único modelo racional de radiador, diseñado en Francia por Francis Jourdain, que responde al mismo tiempo a las necesidades calóricas y a las estéticas.

${ }^{3}$ Este debate es el hilo conductor en BRANDT, Edgar, "L' Art et le fer", en Les arts décoratifs modernes, Paris, Les éditions G. Cres et Cie, 1925, pp. 131-141. Aquí, el que era ya entonces el más prestigioso ferronnier francés aboga sin discusiones por el uso de técnicas industriales, que él mismo aplicaba y que fueron decisivas para incrementar y diversificar su producción. V. en este sentido KAHR, Joan, Edgar Brandt: Master of Art Déco Ironwork, New York, Harry N. Abrams, 1999.

${ }^{4}$ Uno de estos casos excepcionales se encuentra en el palacio sevillano de José Lissén Hidalgo, construido y decorado siguiendo las pautas del estilo regionalista entre 1918 y 1919. Los cubrerradiadores, firmados por el artista madrileño del hierro Luis Barrera, son de hierro forjado y desarrollan un motivo renacentista a base de volutas, búcaros, balaustres y pabellones.

${ }^{5}$ El interés de la fotografía en el caso de un artista como Juan José, cuya obra en buena parte ha desaparecido o se encuentra en paradero desconocido, fue analizado en HERRADÓN FIGUEROA, Ma Antonia, "Raros y olvidados: dos archivos fotográficos de artistas en el Museo del Traje, Centro de Investigación del Patrimonio Etnológico", en Actas de las Cuartas jornadas Imagen, cultura y tecnología, Madrid, Universidad Carlos III, 2006, pp. 61-73. Por su parte, estas series documentales han estado custodiadas por la Fundación Juan José desde 1962 hasta 2015. En la actualidad forman parte de las colecciones del Museo del Traje, CIPE de Madrid (en adelante MT).

${ }^{6}$ Urgoiti, madrileño de ascendencia vasca, fue, especialmente entre 1900 y 1936, una de las figuras más destacadas del mundo empresarial y cultural español. De profundas convicciones liberales, empresario vinculado con el sector papelero y con la prensa escrita, fue uno de las grandes figuras de nuestra Edad de Plata. También fue el más destacado comitente que Juan José tuvo en sus primeros años de ejercicio profesional, una etapa en la que tanto los contactos personales como la venta de piezas son extraordinariamente importantes para todos los artistas. La mayor parte de las piezas realizadas por Juan José para Urgoiti se han conservado en manos de la familia.

${ }^{7} \mathrm{~N}^{\mathrm{o}}$ inv. CE114929, MT.

${ }^{8}$ Se han conservado su diseño y una fotografía de la pieza terminada. № inv. CE114928 y FD064809, MT.

${ }^{9}$ Fue publicada en GARCÍA, Juan José, Algunas obras del taller de Juan José García, [Madrid, s. n., 1924], descrita como "cubrechimenea de hierro repujado de estilo Renacimiento". Su precio era de 1.500 pts.

${ }^{10}$ Figuran propuestas de decoraciones interiores historicistas en Arte y decoración en España. Arquitectura. Arte decorativo. 10 vols., Barcelona, V. Casellas Montcaut, 1917-1927, y CABELLO LAPIEDRA, Luis María, La casa española. Consideraciones acerca de una arquitectura nacional, Madrid, Sociedad Española de Amigos del Arte, 1920. Un ejemplo de la pervivencia de esta tendencia es el de la decoración neorrenacentista de la casa de Ricardo Sánchez Cuenca en Calatayud (Zaragoza), construida entre 1928 y 1929 y estudiada en POBLADOR, María Pilar, "Espacios ayer vividos y hoy olvidados. La fotografía como fuente para la recuperación del ambiente y la decoración de la arquitectura zaragozana de comienzos del siglo XX", en Espais interiors. Casa $i$ art des del segle XVIII al XXI, Barcelona, Universitat de Barcelona, 2007, pp. 433-447.

${ }^{11}$ Para componer el panel decorativo el artista utilizó aquí, en lugar de una plancha única recortada y cincelada, una serie de volutas soldadas entre sí, lo que constituye una solución técnica excepcional en el conjunto de su obra. En caso necesario Juan José siempre se decantó por el machihembrado de las diferentes partes y por el uso de remaches de hierro.

${ }^{12} \mathrm{~N}^{\mathrm{o}}$ inv. CE114142, MT.

${ }^{13}$ Se trata del diseño $N^{\circ}$ inv. CE114872, MT. 
${ }^{14}$ Se han conservado los diseños previos (dos diferentes, aunque con los mismos motivos), el dibujo de taller y la
fotografía de la pieza terminada. No inv. CE114643, CE115410 y FD062920, MT.
${ }^{15}$ Este diseño de hojas lanceoladas fue utilizado por el artista para decorar los paneles laterales de, al menos, tres
cubrerradiadores, entre ellos dos de los instalados en su domicilio. V. figs. 2 y 5 .
${ }^{16}$ Véase HERRADÓN FIGUEROA, M ${ }^{a}$ Antonia, "Artes decorativas para tiempos modernos (1919-1936). Juan
José y la Exposition Internationale des Arts Décoratifs et Industriels Modernes, París 1925", en Patrimonio
Cultural de España, No 10 , Madrid, 2015, pp. 46-57
${ }^{17}$ En el caso del Lyceum Club es probable que los cubrerradiadores se instalaran en su sede definitiva, en la calle San Marcos 44.

${ }^{18}$ DIEGO BARRADO, Lourdes, El arte de la forja a través de los siglos, Oropesa del Mar, Luis Elvira, 2003, p. $141, \mathrm{n}^{\circ}$ cat. 453 . Se conservan el dibujo de taller y una fotografía de la pieza terminada. $\mathrm{N}^{\circ}$ inv. CE115406 y FD062923, MT.

${ }^{19}$ Este animal, junto con el ciervo, uno de los símbolos por excelencia del certamen parisino, y en cierta medida una de las iconografías estrella del art déco, ya habían sido utilizado en repetidas ocasiones por el artista con anterioridad a su estancia en París. Por ejemplo, en varios paneles ornamentales, entre ellos el que decoraba el bar del Monumental Cinema de Madrid, fechado en 1923, así como en diversos platos y tazas contemporáneos.

${ }^{20}$ Se conservan el dibujo de taller y una fotografía de la pieza terminada. $\mathrm{N}^{\circ}$ inv. CE115407 y FD062928, MT.

${ }^{21}$ Se conservan el dibujo de taller y dos fotografías de las piezas terminadas. $\mathrm{N}^{\mathrm{o}}$ inv. CE114305, FD062921 y FD062922, MT.

${ }^{22}$ Se conservan las fotos de las piezas terminadas. $\mathrm{N}^{\circ}$ inv. CE062932 y FD062933, MT.

${ }^{23} \mathrm{~N}^{\mathrm{o}}$ inv. CE113865, MT.

${ }^{24}$ Salvador Carreras fue el arquitecto que diseñó en 1915 la fábrica de la Perfumería Gal, situada al final de la calle Princesa de Madrid. En este contexto coincidió con Juan José, cuya relación con la empresa perfumera fue muy estrecha hasta los años 30, siendo especialmente intensa a lo largo de la segunda mitad de la década de 1910. Por un lado, sus dibujos fueron insertados en la prensa ilustrada para publicitar las creaciones de la firma. Por otro, al artista diseñó para la casa cartones para vidrieras, que luego ejecutaría la afamada empresa vidriera Mauméjean, con la imagen de una muchacha a la griega portando una guirnalda de flores. Asimismo, firmó varias lámparas de estilos neohistoricistas, acordes con el tono general de la construcción, para diversas estancias del complejo fabril.

${ }^{25}$ Se conservan el diseño, el dibujo de taller y una fotografía de la pieza terminada. $\mathrm{N}^{\circ}$ inv. CE114924, CE115685 y FD062926, MT.

${ }^{26}$ La compañía de Ferrocarriles del Norte finalizó en 1928 la construcción de un nuevo edificio de cabecera destinado a salidas. En su estética confluían desde el historicismo clasicista hasta el pseudo barroco, presente en el salón de autoridades, pasando por el art déco del bar. Aunque parece que en el encargo se mencionan varios cobertores de radiador, entre ellos los de la sala de espera regia, sólo se ha conservado el dibujo y la fotografía de uno de ellos. $\mathrm{N}^{\circ}$ inv. CE114937 y FD062934, MT.

${ }^{27}$ Se conserva el diseño $\mathrm{N}^{\mathrm{o}}$ inv. CE114933, MT.

${ }^{28}$ Se conserva el diseño. $\mathrm{N}^{\circ}$ inv. CE114923, MT. De la segunda variante se conservan el diseño de taller y una fotografía de la pieza terminada. $\mathrm{N}^{\circ}$ inv. CE115675 y FD062924, MT.

${ }^{29}$ DIEGO BARRADO, Lourdes, El arte, cit., p. 140., n ${ }^{\circ}$ cat. 86. Se conservan el diseño, el dibujo de taller y una fotografía de la pieza terminada. $N^{\circ}$ inv. CE114925, CE115648 y FD062930, MT.

${ }^{30}$ Se conserva el dibujo de taller. $\mathrm{N}^{\circ}$ inv. CE115403, MT.

${ }^{31}$ Se conserva el dibujo de taller. $\mathrm{N}^{\circ}$ inv. CE114934, MT.

${ }^{32}$ HERRADÓN FIGUEROA, Ma Antonia, Artes decorativas, cit., pp.49-51.

${ }^{33}$ Del primero se conservan el diseño, el dibujo de taller y una fotografía. $\mathrm{N}^{\circ}$ inv. CE114939, CE115400 y FD062925, MT. Del segundo, sólo el dibujo de taller. Nº inv. CE115394, MT.

${ }^{34} \mathrm{~V}$. nota 5.

${ }^{35}$ CLARÁ AYATS, José, [Del arte decorativo moderno] Discurso leído ante la Real Academia de Bellas Artes de San Fernando en la recepción pública del señor don José Clará y Ayats, Madrid, Real Academia de Bellas Artes de San Fernando, 1925, p. 10. 
${ }^{36}$ JANNEAU, Guillaume, Le fer à l'Exposition Internationale des Arts Décoratifs Modernes, Paris, F. Content, 1925 , p. 3.

${ }^{37}$ Lo mismo cabe señalar de otras obras contemporáneas de Juan José, todas encuadradas dentro de las artes decorativas: ilustraciones, lámparas, apliques de luz, rejas, puertas, muebles, platos, bandejas, esculturas, encuadernaciones, jarrones, etc.

${ }^{38}$ PÉREZ ROJAS, Francisco Javier, Art déco en España, Madrid, Cátedra, 1990, pp. 23 y 240.

${ }^{39}$ En ninguna de las dos grandes publicaciones recientes sobre el tema, Art deco: 1910-1939, London, Victoria \& Albert Publications, 2003 y 1925. Quand l'art déco séduit au monde, Paris, Norma Ed., 2013 se hace referencia a la manifestación y desarrollo en España del art decó, una evidencia cuya negación a esas alturas carece de justificación.

40 PALLOL, David, Madrid Art Déco, Madrid, La Librería, 2012, y PÉREZ ROJAS, Francisco Javier, "Presencia del art déco en España", en El gusto moderno. Art Déco en París 1910-1935, Madrid, Fundación Juan March, 2015, pp. 189-203.

Fecha de recepción: 01-12-2017

Fecha de revisión: 25-12-2017

Fecha de aceptación: 18-01-2018 